\title{
Spatiotemporal Climate Change and Resilience through Nature Conservation in Ethiopia
}

\author{
Abbadi Girmay Reda ${ }^{1 *}$ and Nitin K Tripathi ${ }^{2}$ \\ ${ }^{1}$ Senior Researcher, Tigray Agricultural Research Institute, Ethopia \\ ${ }^{2}$ Remote Sensing \& GIS, Asian Institute of Technology (AIT), Thailand \\ Submission: January 02, 2018; Published: April 09, 2018 \\ "Corresponding author: : Abbadi Girmay Reda, Senior Researcher, Tigray Agricultural Research Institute, Ethiopia, \\ Email: Abbadigirmayreda@gmail.com
}

\begin{abstract}
This paper deals with application of geospatial techniques for climate change detection in Ethiopia for the period of 1946 to 2006; case study of point data analysis of semi-arid environment of Ethiopia (Mekelle station) for the period of 1980 to 2010 to detect and describe spatio-tempotal trends and changes occurred during the study period; and assessment of SLM practices and their impacts on environmental rehabilitation, livelihoods, agricultural production, and contribution to climate change resilience. Geospatial analysis was executed in ARCGIS 10 to generate spatiotemporal climate change difference maps for the indicated 60 years. Descriptive statistics was applied to summarize data with measure of central tendency and measure of variability and dispersion. The variability of climate variables over the study period was examined by calculating coefficient of variation (CV). Mann-Kendall test was applied for time series trend analysis of temporal trend of climate variables. The Ethiopian climate has shown a drastic spatiotemporal climate change in the last 60 years (1946-2006) which manifests the impact of global warming at local level. There was an increasing trend of both maximum and minimum temperature while there was no consistency in rainfall patterns. Maximum temperature of April increased by $2.1^{\circ} \mathrm{C}$ during the period of 1946 to 2006 . The strong inter-annual and inter-decadal variability in Ethiopia's rainfall makes it difficult to detect long-term trends. However, rainfall trend through 1946 to 2006 for moist areas of Western and South Western Ethiopia are showing downward (negative) trend of rainfall which indicates that their forest covers have been deteriorating through time. However, interestingly, the Northern Ethiopian regions show positive (upward) trends owing to massive environmental rehabilitation and restoration of degraded lands into productive lands in the last 25 years. Region-specific detailed and seasonal climate studies are needed and to be integrated with local context of agriculture, livelihoods, forecasts, and development plans for effective Early Warning Systems to utilize climate potentials and minimize natural disasters. This original work dealing with nationwide spatiotemporal trend is of its first kind in Ethiopia and will serve as a milestone for further detailed agroclimatic and sector-based analysis of spatiotemporal climate change and variability patterns, impact assessment, and adaptation and mitigation strategies.
\end{abstract}

Keywords: Ethiopia; Climate change detection; GIS; Spatiotemporal analysis, Mitigation; SLM

Abbreviations: NAPA: National Adaptation Program of Action; SLM: sustainable land management; CRU: Climate Research Unit; IWMI: International Water Management Institute

\section{Introduction}

World Bank (2006) asserts that rainfall variability costs the Ethiopian economy 38\% of its potential growth rate. Net revenue per hectare will be reduced by USD 177.62 and 464.71 consequent to a unit increase in temperature during summer and winter seasons, respectively. Climate change is therefore a threat to the Ethiopian economy. The available option for Ethiopia to reduce the wide-ranging impacts of climate change is to develop mitigation strategy for resilience. Vulnerabilities are local and require location specific adaptation and mitigation measures. Ethiopia is expected to be hardest hit by climate change and the most vulnerable sectors are agriculture, water resources, and human health (C. Arndt et al., 2009, GEF, 2009). This can significantly reverse the progress towards poverty reduction and food security in Ethiopia. Analyzing and assessing the spatiotemporal climate change trends would help better understand impacts of climate change to formulate better strategies for climate change adaptation and mitigation in Ethiopia and encourage local proactive community participation and national efforts as a contribution to global climate change mitigation. Proactive approaches to managing climate risks within vulnerable rural communities and among institutions operating at community, sub-national, and national levels is a crucial step towards achieving the sustainable economic development [1-7].

The Ethiopian National Adaptation Program of Action (NAPA) recognized sustainable land management (SLM) as a major mitigation strategy. Experiences from elsewhere such as in China have shown that appropriate use and management of natural resources could enhance resilience of ecosystems and improve livelihoods of the poor in the face of climate change [8$10]$. 
This article deals with application of geospatial techniques for climate change detection in Ethiopia for the period of 1946 to 2006; case study of point data analysis of semi-arid environment of Ethiopia (Mekelle station) for the period of 1980 to 2010 to detect and describe spatiotemporal trends and changes occurred during the study period; and assessment of SLM practices and their impacts on environmental rehabilitation, livelihoods, agricultural production, and contribution of SLM to climate change resilience.

\section{Materials and Methods}

\section{Data acquisition}

Data (1980-2010) from semi arid Ethiopia (Mekelle station): The data set included maximum temperature for the hot season (April-June), minimum temperature for the cold season (October-January) and seasonal rainfall for the period of 1980-2010.

Climate Research Unit (CRU) dataset: Raster climate data including maximum temperature for warm season (AprilJune), cold season (October-January) and rainfall for the rainy season (June-September) for the years 1946 and 2006 were extracted from CRU Geospatial Raster Data Portal for Ethiopia to detect climate change in 60 years time period. The data has been produced by the CRU of University of East Anglia (UEA), and reformatted by International Water Management Institute (IWMI) to provide for easy access and to use in geospatial analysis using common GIS software.

Geospatial operations: Stacking, Spatial Analysis, Map calculation, overlaying and change detection were executed in ENVI 4.7 and ARC GIS 10 to generate spatiotemporal climate change difference maps for the indicated 60 years.

Statistical analysis: Descriptive statistics was applied to summarize data with measure of central tendency and measure of variability or dispersion (standard deviation and variance), the minimum and maximum variables. Descriptive summary was prepared for each parameter. Coefficient of variation (C.V.) was reported as a percentage value for each parameter. The variability of climate variables over the study period was examined by calculating coefficient of variation (CV). MannKendall test (Gilbert, 1987, Kendall, 1975) was applied for time series trend analysis of temporal trend of climate variables. Non Parametric time series Mann Kendall trend test is adopted for testing temporal trend of climate variables as recommended by WMO [11-13]. Softwares used included ENVI 4.7, ARC GIS 10, Excel and SPSS.

\section{Results and Discussion}

\section{Parameter values as compared to pixel values}

Temperature and rainfall of pixel value is calculated by dividing each pixel value by 10 and the actual values of parameters are the figures indicated in each map divided by 10 (e.g. the value of rainfall appearing in the map is 12750 the actual rainfall would be $1275 \mathrm{~mm}$ and the same applies for temperature. Temperature of 183 in the map legend would mean the actual temperature is $18.3^{\circ} \mathrm{C}$ ).

\section{Spatiotemporal climate Change, Ethiopia (1946- 2006)}

Rainfall: 1946 monthly rainfall (June-September) showed that August received the highest rainfall (580mm), July $(448 \mathrm{~mm})$ followed by September $(398 \mathrm{~mm})$ and June(369mm). 2006 monthly rainfall shows August received $366 \mathrm{~mm}$, July $441 \mathrm{~mm}$, September $(255 \mathrm{~mm})$ and June $(294 \mathrm{~mm})$. There was a clear shift of monthly intensity of rainfall from 1946 to 2006. In 1946, the pick rainy month was August but in 2006 it was shifted to July. Likewise, in 1946 June received the least amount of rainfall but in 2006 it increased in amount and replaced September where September received the least rainfall amount in 2006. Rainfall change during 1946 to 2006 was calculated as the difference between 1946 and 2006 seasonal rainfall and it is simply directional trend between the two time periods as shown in Figure 2. Rainfall generally shows declining trend from 1946 to 2006. Moist areas of Western and South Western Ethiopia are showing fall of rainfall showing their forest covers have been deteriorating through time. Interestingly, the drier areas show some positive trends owing to massive environmental rehabilitation and restoration of degraded lands into productive lands in the last 25 years.

Maximum temperature variation (April- June, 19462006): Maximum temperature for the months April through June for both 1946 and 2006 was computed with same procedure for rainfall and changes in monthly maximum temperature are detected for each month. Maximum temperature of April increased by $2.1^{\circ} \mathrm{C}$ during the period of 1946 to 2006 .

Minimum temperature variation (October- January, 1946-2006): Minimum temperature shows two extreme facts. In some areas it is falling down than before indicating that they are becoming cooler than before. In other areas, minimum temperature is rising up that places that were very cold are decreasing their coldness. These data are in support of Ethiopian Meteorological Agency records. These data are evidence of global climate change for the existence of extreme weather changes justifying that some areas unusually are becoming cold and some becoming warmer and hotter than before because of global warming.

\section{Case study: Temporal climate variation of point data (Mekelle station, 1980-2010)}

Temporal climate trend: Rainfall had no significant trend during 1980-2010 period based on XLSTAT 2012 parametric and non- parametric trend tests. Maximum temperature and rainfall had no significant trend (Table 1).

Minimum temperature (October-January) was highly variable with coefficient of variation ranging $11 \%$ to $23 \%$ whereas maximum temperature was stable with minimum variation during the period of 1980 to 2010 (Figure 1). 
Minimum temperature (October-January) showed significant increasing trend while maximum temperature and rainfall had no significant trend during 1980-2010 period. Minimum temperature of October had the highest increasing rate of $0.026^{\circ} \mathrm{C} /$ annum. This increasing trend of minimum shows those seasons are getting hotter in recent years. Years of 1980, 2001 and 2006 were relatively wet years while year 1984 was the driest year manifested by the worst 1984 drought in Northern Ethiopia. Minimum temperature of the cold season (OctoberJanuary) is rising up.

Table 1: Temporal trend of climate variables at Mekelle (1980-2010).

\begin{tabular}{|c|c|c|c|c|c|c|}
\hline & Variable & $\mathbf{R 2}$ & Standard error & $\mathbf{F}$ & P-value & Trend \\
\hline \multirow{3}{*}{$\begin{array}{c}\text { Maximum } \\
\text { temperature }\left({ }^{\circ} \mathrm{C}\right)\end{array}$} & April & 0.003 & 0.07 & 0.102 & 0.75 & $\begin{array}{l}\text { NS (No significant } \\
\text { trend) }\end{array}$ \\
\hline & May & 0.052 & 0.02 & 1.2 & 0.29 & $\begin{array}{c}\text { NS (No significant } \\
\text { trend) }\end{array}$ \\
\hline & June & 0.0005 & 0.025 & 0.029 & 0.87 & $\begin{array}{c}\text { NS (No significant } \\
\text { trend) }\end{array}$ \\
\hline \multirow{4}{*}{$\begin{array}{c}\text { Minimum } \\
\text { temperature }\left({ }^{\circ} \mathrm{C}\right)\end{array}$} & October & 0.26 & 0.021 & 9.6 & 0.005 & Significant trend \\
\hline & November & 0.21 & 0.029 & 7.1 & 0.014 & Significant trend \\
\hline & December & 0.21 & 0.036 & 6.5 & 0.018 & Significant trend \\
\hline & January & 0.22 & 0.03 & 6.4 & 0.019 & Significant trend \\
\hline \multicolumn{2}{|c|}{ Annual rainfall $(\mathrm{mm})$} & 0.154 & 2.1 & 4.2 & 0.052 & $\begin{array}{l}\text { NS (No significant } \\
\text { trend) }\end{array}$ \\
\hline
\end{tabular}

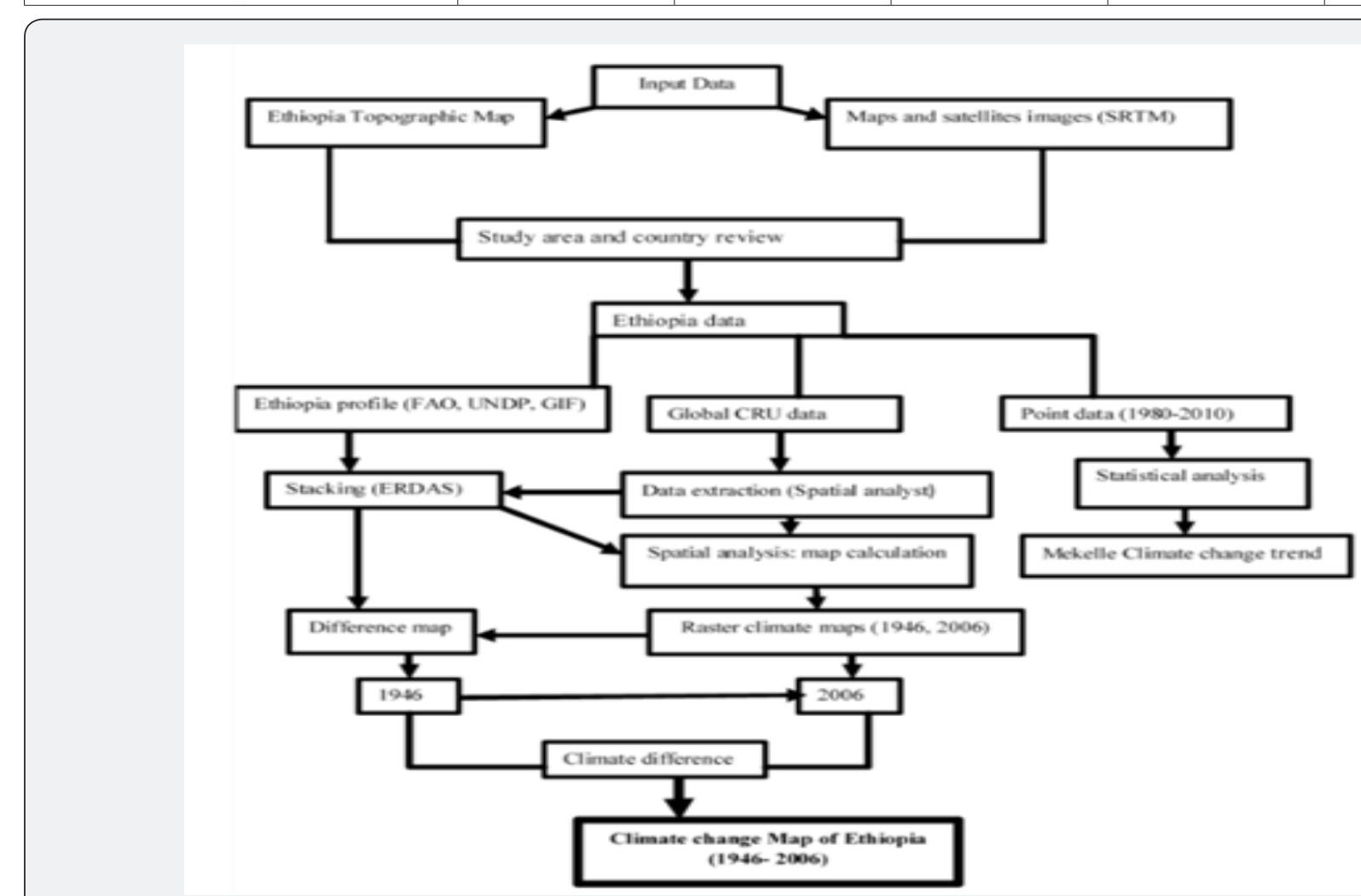

Figure 1: Study flowchart.

SLM for climate change resilience in Ethiopia: An option for adaptation to climate change and necessary condition for sustainable agriculture in itself is sustainable land management (SLM) and rehabilitation of degraded lands. Environmental rehabilitation efforts in Ethiopia have brought about reclamation of waste lands, revegetation of degraded hillsides, restoration of damaged pasturelands, and adoption of improved soil and water conservation and management technologies in cultivated lands. SLM practices and climate change adaptation and mitigation strategies are mutually supportive and represent win-win options. It is a multisectoral and multi-stakeholder program that brings communities, the government and the supporting institutions on common platform and towards shared results. The overall objective of SLM Program is to improve the livelihood 
of land users and communities through implementation of SLM activities in the framework of community based participatory watershed development plans [14].

The overall impacts of SLM in Ethiopia include: Reclamation of gully and degraded lands in to productive lands; enhanced surface and ground water availability; modification of microclimates; increased productivity; soil fertility and moisture availability enhanced use of chemical fertilizers; environmental and ecological rehabilitation; habitat and biodiversity restoration; feed and water availability for livestock; and overall impacts on household incomes and livelihood outcomes [15-25].

\section{Conclusion}

The Ethiopian climate has shown a drastic spatiotemporal climate change in the last 60 years (1946-2006) which manifest the impact of global warming at local level. Our findings were in line with global trends of temperature and rainfall changing patterns. CRU is one of the huge climate resource data center with its raster global climate data portal for the period of 1901 to 2006. GIS has efficient tools to extract, manipulate and analyse global data in to area of interest and generate spatial data within short time. It can help us analyses spatiotemporal climate change. There was an increasing trend of both maximum and minimum temperature while there was no consistency in rainfall patterns. Detailed agroclimate based analysis is required to generate high spatial resolution outputs with locally specific application for climate change assessment and design effective adaptation strategies in the face of climate change. Synergy is needed to complement local climatological knowledge and build capacity of community for early Warning System at local level to better utilize (exploit) climatological potentials and minimize risks due to natural disasters. The results of this study will serve as a milestone for further detailed analysis and impact assessment studies. The Kyoto period is the lost opportunity for Africa. Ethiopia as one of the hardest hit countries by global climate change has developed climate change adaptation and mitigation strategies (NAPA and NAMA) and has mobilized its resources and implements different projects. This lead national effort in Africa should be appreciated and be supported by international initiatives such as The Copenhagen Negotiation and other UNbased frameworks. This effort is also development pathway for Ethiopia.

\section{References}

1. Temesgen D, Rashid MH Ringler C (2008). Measuring Ethiopian Farmers' Vulnerability to Climate Change across Regional States. IFPRI Discussion Paper 2008, discussion paper number 00806.
2. FAO (2007) Adaption to climate change in agriculture, forestry and fisheries: Perspectives, frameworks and Priorities.

3. FAO (2010) Climate change threat to Africa: Adaptation a priority.

4. IPCC WG (2007) IPCC Fourth Assessment Report: Climate Change (AR4).

5. Cheung WH, Gabriel BS Ashbindu S (2008) Trends and Spatial Distribution of Annual and Seasonal Rain fall in Ethiopia. International Journal of Climatology 28(3): 1723-1734.

6. Abbadi Girmay Reda, Nitin K Tripathi (2011) Mainstreaming Climate Change Adaptation in Urban Planning in Africa. In USMCA 2011 International Symposium, Thailand.

7. Sweemy et al. (2010) UNDP Climate Change Country Profiles.

8. NMSA (2008) Climate change adaptation taskforce and plans.

9. IFPRI (2010) Climate Change impacts in Ethiopia and South Africa.

10. FDRE (2008) Ethiopia Country reports.

11. WMO (1996) Standard climatological year of 1961-1990.

12. WMO (2009) Addressing climate information needs at the regional level. WMO bulletin 58(3).

13. IPCC (1994) Technical Guidelines for Assessing Climate Change Impacts and Adaptations with a Summary for Policy Makers and a Technical Summary.

14. Wolde AB (2009) Environmental rehabilitation in response to climate change in Ethiopia. WFP, MERET Project Evaluation report, Ethiopia.

15. Girmay AR, Tripathi KN (2010) Climate change adaptation through environmental rehabilitation in Ethiopia. Proceedings of third International Conference on Geo information Technology for Natural Disaster Management, Thailand, p. 9-13.

16. Ahmed H, Robinson S, Willenbekel D, Arndt C (2009) Climate change and Ethiopia. (Volume 6), Earth and Environmental Sciences.

17. MoARD (2004) Environmental rehabilitation activities (1979-1999).

18. GEF (2006) Coping with drought and climate change. Ethiopia.

19. Hansen JW (2005) Integrating seasonal climate prediction and agricultural models for insights into agricultural practice. Philosophical Transactions of the Royal Society 360(1463): 2037-2047.

20. https://www.nasa.gov/topics/earth/features/indian_ocean_warm. htm

21. NASA (2012) Recent drought and precipitation tendencies in Ethiopia.

22. World Weather Information Service (http://worldweather.wmo. int/060/c00167.htm).

23. www.cgiar-csi.com (accessed on 20/05/ 2012).

24. www.esri.com (accessed on 11/03/2013).

25. www.uea.ac.uk/climatic_research_unit/ (accessed on 21/04/2012). 
This work is licensed under Creative Commons Attribution 4.0 License
Your next submission with Juniper Publishers will reach you the below assets

- Quality Editorial service

- Swift Peer Review

- Reprints availability

- E-prints Service

- Manuscript Podcast for convenient understanding

- Global attainment for your research

- Manuscript accessibility in different formats

( Pdf, E-pub, Full Text, Audio)

- Unceasing customer service

Track the below URL for one-step submission https://juniperpublishers.com/online-submission.php 